\title{
DEMOGRAPHIC INFLUENCES ON THE NUMBER OF CHILDREN AT SCHOOL ENTRY AGES, WITH EXAMPLES FROM THREE STATES
}

\author{
Carl P. Schmertmann, T. J. Mathews, and Charles B. Nam*
}

\begin{abstract}
When demographic rates are in flux, each age group within a regional population grows at a different rate. This paper analyzes the effects of changes in fertility, mortality, and net migration patterns on the growth of school entry-age populations in three states (Florida, South Carolina, and West Virginia) over the period 1950-1990. Fertility changes have had the largest influence on growth of these young populations, as common sense suggests. Changing migration patterns have been quite important, however, in explaining intertemporal and interspatial variations in growth rates. Furthermore, migration's effects on age-specific growth rates can be counterintuitive. Most importantly, sustained net in-migration does not necessarily generate positive growth of age-specific populations within a state. We discuss some implications for policy and for improving population projections.
\end{abstract}

\section{INTRODUCTION}

Regional populations grow or decline at different rates, depending on differences in three primary components of population change-fertility, mortality, and migration. Differences in these components, particularly migration, account for large variations in population growth across U.S. regions and states (Smith and Ahmed 1990).

It is natural to compare population growth across regions, but intraregional differences are often equally interesting and important. For example, different age groups within a state may have different growth rates. As with interregional variation, such differential population growth often has significant economic consequences. Entry-level jobs may be difficult to obtain if the young adult population is growing more rapidly than other age groups; state-funded programs for the elderly may face severe crises if the age group 65 and over grows faster than the population 0 to 64; an increasing proportion of taxes must be spent on education if the number of young children grows faster than the rest of the population; and so forth. It is therefore interesting to ask how the demographic forces that determine overall regional populations affect the growth of age-specific subpopulations within regions.

\footnotetext{
*Department of Economics, Florida State University; National Center for Health Statistics; Department of Sociology, Florida State University, respectively.
} 
New demographic methods allow a systematic study of these questions. Demographers, motivated by the study of aging in national populations, have created mathematical tools for analyzing age-specific growth rates (e.g., Preston and Coale 1982; Horiuchi and Preston 1988; Preston, Himes, and Eggers 1989).

In a recent application in regional science, Ahmed and Smith (1992) examined the components of the population aging in individual U.S. states. They concluded that "population momentum" was the primary source of aging in most states in the decades between 1950 and 1980. Momentum measures the effect of a state's initial age distribution on the aging process over a decade. ${ }^{1}$ Because past fertility trends strongly influence this initial distribution, Ahmed and Smith's results indicate (sensibly) that past fertility patterns are an important component of age-specific growth patterns within states. ${ }^{2}$ Ahmed and Smith also found that differences in migration rates are the principle source of interstate variation in population aging.

In this paper, we extend analysis of state- and age-specific population change to an important age group that has so far received little attention-children at school entry ages (5-6 year olds). Fluctuations in school entry-age populations (called "SE" populations from here on) clearly have meaningful policy implications for state governments.

At first glance, evaluating the demographic reasons for the relative growth or decline of very young age groups may seem trivial. One might expect states' SE population growth to be determined nearly completely by recent fertility trends. Our analysis, however, shows that this is not always true at the state level. Trends in the interstate migration of children can have significant effects on SE population growth. In addition, as we demonstrate below, the effects of migration on SE population change are often counterintuitive.

We do not intend in this paper to propose a new method of making statelevel SE population projections. Instead, we have two more basic goals. The first is purely illustrative. By means of selected examples, we document significant variations, across states and over time, in age-specific growth rates and in their underlying demographic causes.

Our second goal is analytical. By evaluating the relative importance of fertility, mortality, and migration trends in past growth in our examples, we provide information on the sensitivity of age-specific population projections to various demographic assumptions. Knowledge of this sort should improve our overall understanding of growth in age-specific populations at the state level, particularly at young ages. It therefore will allow regional planners and researchers to better understand and anticipate trends in the many areas of economic and social inquiry in which age-specific population growth plays a role. 


\section{EXAMPLES: SE POPULATION GROWTH IN THREE STATES}

Rather than create an extensive catalog of the sources of growth of 5-6- yearolds for all 50 states, we have chosen to intensively analyze selected examples. After preliminary analysis (Nam and Mathews 1991), we chose three statesFlorida, South Carolina, and West Virginia-for detailed study. ${ }^{3}$ The decision to use southern states was arbitrary, but we selected this particular set because they represent very different trajectories for SE populations between 1950 and 1990. These three states began the postwar period with similar SE populations: in 1950 there were approximately 103,000 5-6-year-olds in Florida, 101,000 in South Carolina, and 83,000 in West Virginia. Over the next 40 years, however, Florida's SE population more than tripled, while South Carolina's was virtually constant (a 1 percent increase over 40 years), and West Virginia's decreased by 45 percent.

Figure 1 illustrates average annual intercensal growth rates for both the total and the SE populations in the three selected states over the period 1950-1990. The bottom right panel summarizes the differences between SE and total population growth rates for all three states.

Several features of Figure 1 merit comment. First, age groups can obviously grow at rates that differ dramatically from the overall population growth rate. One sees this clearly in cases where the growth rates for the SE and the total state populations have opposite signs; this occurs in 4 of 12 cases illustrated in Figure 1. In perhaps the most startling example, the number of 5-6-year-olds in Florida actually declined in the 1970 s, even as the total state population grew very rapidly.

Second, states exhibit similar intertemporal pattems in the differences between SE and overall growth rates (see bottom right panel). In all three states, SE growth was slightly higher than total population growth in the 1950 s, lower in the 1960s, and still lower in the 1970s. Informed intuition suggests that these similarities are most likely the result of common fertility trends, with high SE growth in the 1950s corresponding to increasing fertility during approximately 1945-55, and the low SE growth of the 1960s and 1970s corresponding to falling fertility after the mid-1950s. We verify this intuition in the formal analysis below.

Third, despite some fundamental similarities in Figure 1, each state's history appears to be unique in some way. This is particularly true in 1970-90, a period in which there was considerably more cross-state variation in differences between SE and total growth than there had been between 1950 and 1970. Common fertility trends could not explain these differences, suggesting that other demographic factors may also be at work.

The next sections formalize the analysis of Figure 1 and report and interpret the results. 


\section{FIGURE 1}

Average Annual Intercensal Growth Rates-Florida (F), South Carolina (S), and West Virginia (W)

Florida

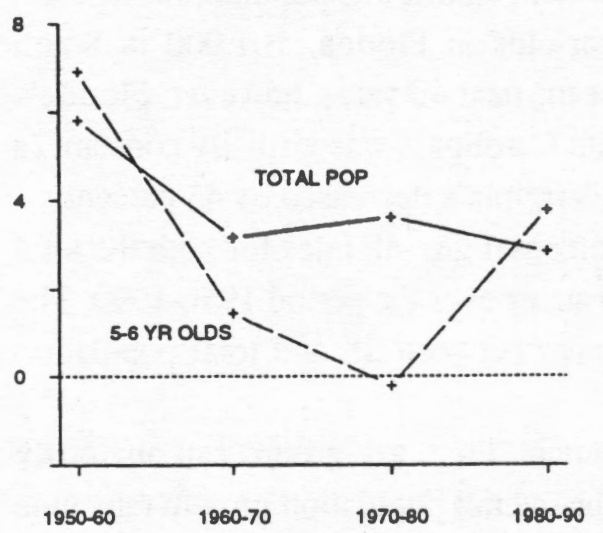

West Virginia

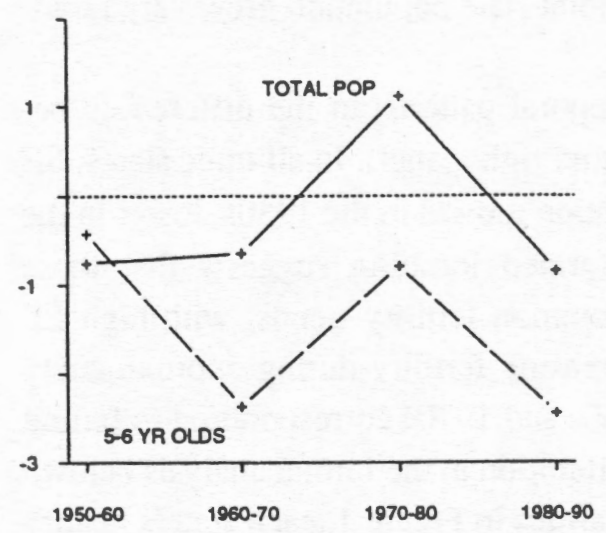

South Carolina

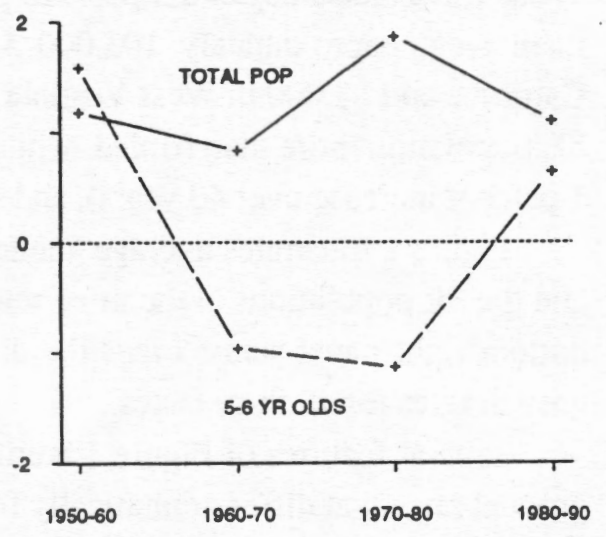

SE minus Total Growth Rate

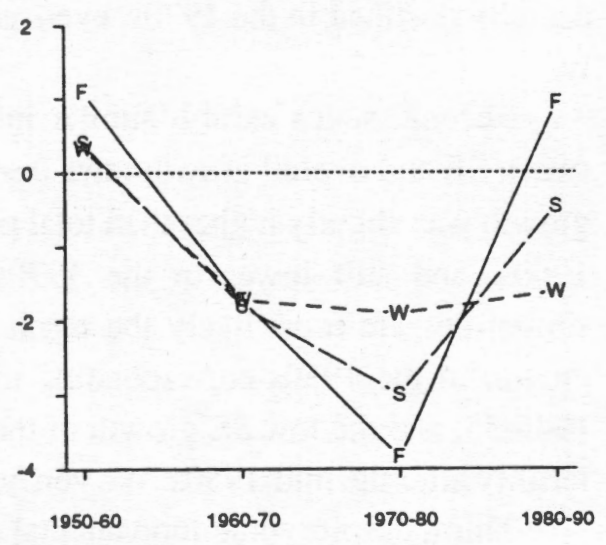




\section{DEMOGRAPHIC COMPONENTS OF AGE-SPECIFIC GROWTH}

\section{Decomposition Method}

Following the logic of Preston et al. (1989, eq. 5), we define the number ${ }^{4}$ of $x$-year-old residents of a state at time $t$ as

$$
N_{x}(t)=B(t-x) s_{x}(t-x) m_{x}(t-x)
$$

where $B(t-x)$ is the number of births in the state at time $t-x, s_{x}(t-x)$ is the fraction of the state birth cohort born at $t-x$ that survived to age $x$, and $m_{x}(t-x)$ is a multiplier representing the effects of net migration (between birth and age $x$ ) of those born at time $t-x$. In much of the analysis below, we disaggregate state births at time $\mathrm{t}-\mathrm{x}$ into components representing the total state population $\mathrm{P}$ and the state crude birth rate $b: B(t-x)=P(t-x) * b(t-x)$.

As in Equation (1), the number of $x$-year-old state residents 10 years later, at time $t+10$, is

$$
N_{x}(t+10)=B(t-x+10) s_{x}(t-x+10) m_{x}(t-x+10)
$$

The growth rate of the state's $x$-year-old population over a decade $(t, t+10)$ is therefore

$$
r\left(N_{\mathbf{x}}\right)=r(B)+r\left(s_{\mathbf{x}}\right)+r\left(m_{\mathbf{x}}\right)=[r(P)+r(b)]+r\left(s_{\mathbf{x}}\right)+r\left(m_{\mathbf{x}}\right)
$$

where we define the average annual rate of change in $N_{x}$ as

$$
r\left(N_{x}\right)=\ln \left[N_{x}(t+10) / N_{x}(t)\right] / 10
$$

and rates of change in the various components-r(B), r(s $), r\left(m_{x}\right), r(P)$, and $r(b)-$ are defined in an analogous way.

Equation (3) decomposes changes in $\mathbf{N}_{\mathbf{x}}$ into demographic components. Each term in Equation (3) implicitly compares two birth cohorts: those turning $x$-years old at the beginning of the decade (born at $t-x$ ), and those turning $x$-years old at the end of the decade (bom at $t-x+10)$. The term $r(P)$ represents the effect of changes in total state population between the birth dates of the two cohorts; it therefore equals the growth in the number of $x$-year-olds that would have occurred if underlying demographic rates $(b, s$, and $m)$ had remained constant. The $r(b)$ term captures the effect of changes in state crude birth rates. ${ }^{5}$ The $r\left(s_{x}\right)$ term reflects changes in the probability that a newbom state native will survive to age $x$. Finally, $r\left(m_{\mathbf{x}}\right)$ captures differences in the effects of migration on the growth or decline of the two cohorts between birth and age $x$. 


\section{Discussion}

An extremely important implication of Equation (3) is that the number of state residents at a given age is determined by the levels of underlying demographic rates, but changes in age-specific population sizes are caused by changes in these rates.

This can be a subtle point when discussing the effects of migration on the number of state residents at any given age $x$. Net in-migration within a cohort between birth and age $x\left(m_{x}>1\right)$ does not guarantee that the region's $x$-year-old population is increasing, even under conditions of constant fertility and mortality. Similarly, net out-migration $\left(m_{x}<1\right)$ does not necessarly imply decreases in the number of $\mathrm{x}$-year-olds. What matters in both cases is a higher-order effect: the direction of change in net migration rates across cohorts.

To fix ideas, consider a simple example. Suppose we are investigating growth of a state's SE population 1980-90. When comparing the size of the 1980

TABLE 1

Growth of a State's SE Population 1980 and 1990

$(1)-(2)+(3)$

Native

Native

Surviving Net

\begin{tabular}{lcccc} 
Birth Cohort & Births & Deaths & In-migrants & SE POPULATION \\
\hline $1973-74$ & 1000 & 10 & +210 & 1200 (in 1980) \\
$1983-84$ & 1000 & 10 & +110 & 1100 (in 1990) \\
\hline
\end{tabular}

SE population with that in 1990 , we are comparing two completely distinct groups of people: the 1980 SE population consisted of individuals born (somewhere) in 1973-74, while the 1990 SE population was bom in 1983-84. Suppose that the number of in-state births in 1973-74 or 1983-84 is given in Table 1 column 1 below, cumulative deaths to these original residents by age 5-6 are in column (2), and cumulative net in-migration by ages 5-6 is in column (3).

Fertility and mortality were constant. Net migration was positive throughout the period in question. What then accounts for the 8.3 percent decrease in the resident SE population between 1980 and 1990 ? It is caused entirely by the downward trend in net migration. The second cohort, despite the fact that it experienced significant increase from migration between birth and ages 5-6, did not grow as much as the first cohort had. The number of 5-6-year-olds therefore fell over the period.

Intuition fails us in this example because we are dealing with a population that has a very high rate of turnover. By definition, no one is a member for more 
than two years. This sort of population requires constant renewal. Today's entries into the population must match yesterday's; otherwise the population declines. ${ }^{6}$

\section{DATA AND CALCULATIONS}

Let us now apply the formal decomposition method of Equation (3) to the data in Figure 1. For each state, the raw data for the decomposition of growth rates consist of annual time series on state births, state infant mortality rates, and state total populations, combined with decennial census counts of state 5-6-yearold populations. ${ }^{7}$

We interpolated census counts, under the assumption of constant geometric growth in the state during the intercensal period, in order to estimate populations on January 1 of each census year; this generated an N5-6 series. ${ }^{8}$ For each state, we calculated $\mathrm{P}$ and $\mathrm{b}$ series from calendar year data on crude birth rates, total populations, and total births. ${ }^{9}$

We estimated cohort infant mortality rates from the calendar year infant mortality data, using the translation method of Shryock, Siegel, and Associates (1976, 237). Published statistics did not allow us to calculate cohort mortality by state beyond age 1 . Consequently, we use $\mathbf{s}_{1}$, the cohort infant survival rate, as our estimate of cohort survival between birth and ages 5-6. We thus implicitly assume that every member of every birth cohort survives the period between their first birthday and the time they are counted as 5-6-year-olds. This assumption is reasonable because cohort survival is in fact very close to 100 percent during these ages, and more importantly because cross-cohort changes in survival rates during these very low-mortality ages should have had virtually no impact on the growth or decline of the populations we are studying. ${ }^{10}$

We estimate migration multipliers $\mathrm{m}_{5-6}$ as a residual, N5-6/Pbs1. Like all residual measures, m5-6 captures the effects not only of migration, but also of any errors in the other data. In our application, these errors include a systematic slight overestimation of cohort survival, due to our substitution of $\mathbf{s}_{1}$ for $55-6$. This will result in a very slight downward bias in all estimates of m5-6. $^{11}$

Table 2 contains the $\mathrm{P}, \mathrm{b}, \mathrm{s}_{1}, \mathrm{~m}_{5-6}$, and $\mathrm{B}$ data used in the calculations. ${ }^{12}$ Table 3 presents growth rates for the SE populations in the three states, r(N5-6), and the calculated contributions of each of the components to those rates. As an example of how to read Table 3, consider the growth of West Virginia's 5-6-yearold population in the $1950-60$ period. The table indicates an overall decrease of 0.42 percent per year, which can be disaggregated into components due to: (1) change in West Virginia's total population between 1943-44 and 1953-54 (+1.11 percent per year); (2) changes in the state's birth rate in that same period 
TABLE 2

Components of Population Change for Various State Birth Cohorts -Florida, South Carolina, and West Virginia

\begin{tabular}{|c|c|c|c|c|}
\hline & & Florida & $\begin{array}{c}\text { South } \\
\text { Carolina }\end{array}$ & $\begin{array}{c}\text { West } \\
\text { Virginia }\end{array}$ \\
\hline \multicolumn{5}{|c|}{ Number of 5-6-year-olds } \\
\hline \multirow[t]{5}{*}{ N5-6 } & 1950 & 101,295 & 100,535 & 82,852 \\
\hline & 1960 & 202,140 & 117,837 & 79,431 \\
\hline & 1970 & 233,388 & 107,046 & 62,693 \\
\hline & 1980 & 228,217 & 95,567 & 57,930 \\
\hline & 1990 & 332,712 & 101,945 & 45,357 \\
\hline \multicolumn{5}{|c|}{ Exposure* } \\
\hline \multirow[t]{5}{*}{$\mathbf{P}$} & $1943-44$ & $4,101,563$ & $3,591,849$ & $3,434,633$ \\
\hline & $1953-54$ & $6,817,817$ & $4,320,313$ & $3,838,246$ \\
\hline & $1963-64$ & $11,184,345$ & $5,028,341$ & $3,593,016$ \\
\hline & $1973-74$ & $16,038,970$ & $5,596,236$ & $3,566,052$ \\
\hline & $1983-84$ & $21,741,190$ & $6,556,628$ & $3,870,556$ \\
\hline \multicolumn{5}{|c|}{ Crude birth rate } \\
\hline b & $1943-44$ & 23.2 & 29.4 & 24.7 \\
\hline \multirow[t]{4}{*}{$(x$ 1000) } & $1953-54$ & 24.2 & 29.5 & 24.2 \\
\hline & $1963-64$ & 20.4 & 22.9 & 19.6 \\
\hline & $1973-74$ & 13.6 & 17.4 & 15.4 \\
\hline & $1983-84$ & 14.0 & 15.4 & 12.9 \\
\hline \multicolumn{5}{|c|}{ Cohort infant survival } \\
\hline $\mathbf{s}_{1}$ & $1943-44$ & 956.5 & 946.2 & 948.0 \\
\hline \multirow[t]{4}{*}{$(x 1000)$} & $1953-54$ & 968.8 & 966.3 & 971.3 \\
\hline & $1963-64$ & 971.7 & 968.4 & 975.3 \\
\hline & $1973-74$ & 982.0 & 978.7 & 981.1 \\
\hline & $1983-84$ & 988.5 & 985.2 & 989.1 \\
\hline \multicolumn{5}{|c|}{ Cohort migration multiplier } \\
\hline m5-6 & $1943-44$ & 1112.9 & 1006.1 & 1032.1 \\
\hline \multirow[t]{4}{*}{$(x 1000)$} & $1953-54$ & 1262.1 & 956.7 & 878.6 \\
\hline & $1963-64$ & 1050.2 & 960.1 & 912.8 \\
\hline & $1973-74$ & 1065.4 & 1003.0 & 1078.7 \\
\hline & $1983-84$ & 1105.7 & 1021.6 & 918.1 \\
\hline \multicolumn{5}{|c|}{ Total state births } \\
\hline \multirow[t]{5}{*}{$\mathrm{B}=\mathrm{Pb}$} & $1943-44$ & 95,162 & 105,611 & 84,676 \\
\hline & $1953-54$ & 165,322 & 127,464 & 93,074 \\
\hline & $1963-64$ & 228,695 & 115,137 & 70,423 \\
\hline & $1973-74$ & 218,130 & 97,354 & 54,739 \\
\hline & $1983-84$ & 304,406 & 101,292 & 49,948 \\
\hline
\end{tabular}

*P measures person-years lived by state residents (all ages) during the two years in which the cohort was born. It is thus approximately equal to twice the average state population during those years. 
TABLE 3

Average Annual Rates of Change in Components Affecting Growth of 5-6-Year-Old Population over Various Decades -Florida, South Carolina, and West Virginia

\begin{tabular}{|c|c|c|c|c|}
\hline & & Florida & $\begin{array}{c}\text { South } \\
\text { Carolina }\end{array}$ & $\begin{array}{c}\text { West } \\
\text { Virginia }\end{array}$ \\
\hline \multicolumn{5}{|c|}{ Number of 5-6-year-olds } \\
\hline \multirow[t]{4}{*}{$r\left(N_{5}-6\right)$} & $1950-60$ & 6.91 & 1.59 & -0.42 \\
\hline & $1960-70$ & 1.44 & -0.96 & -2.37 \\
\hline & $1970-80$ & -0.22 & -1.13 & -0.79 \\
\hline & $1980-90$ & 3.77 & 0.65 & -2.45 \\
\hline \multicolumn{5}{|c|}{ Lagged exposure } \\
\hline \multirow[t]{4}{*}{$\mathrm{r}(\mathrm{P})$} & $1950-60$ & 5.08 & 1.85 & 1.11 \\
\hline & $1960-70$ & 4.95 & 1.52 & -0.66 \\
\hline & $1970-80$ & 3.61 & 1.07 & -0.08 \\
\hline & $1980-90$ & 3.04 & 1.58 & 0.82 \\
\hline \multicolumn{5}{|c|}{ Lagged crude birth rate } \\
\hline \multirow{4}{*}{$r(b)$} & $1950-60$ & 0.44 & 0.03 & -0.17 \\
\hline & $1960-70$ & -1.70 & -2.53 & -2.13 \\
\hline & $1970-80$ & -4.08 & -2.75 & -2.44 \\
\hline & $1980-90$ & 0.29 & -1.19 & -1.74 \\
\hline \multicolumn{5}{|c|}{ Cohort infant survival } \\
\hline \multirow[t]{4}{*}{$r\left(s_{1}\right)$} & $1950-60$ & 0.13 & 0.21 & 0.24 \\
\hline & $1960-70$ & 0.03 & 0.02 & 0.04 \\
\hline & $1970-80$ & 0.11 & 0.11 & 0.06 \\
\hline & $1980-90$ & 0.07 & 0.07 & 0.08 \\
\hline \multicolumn{5}{|c|}{ Cohort migration multiplier } \\
\hline \multirow[t]{4}{*}{ r(m5-6) } & $1950-60$ & 1.26 & -0.50 & -1.61 \\
\hline & $1960-70$ & -1.84 & 0.03 & 0.38 \\
\hline & $1970-80$ & 0.14 & 0.44 & 1.67 \\
\hline & $1980-90$ & 0.37 & 0.18 & -1.61 \\
\hline \multicolumn{5}{|c|}{ Lagged total state births } \\
\hline \multirow[t]{4}{*}{$r(B)$} & $1950-60$ & 5.52 & 1.88 & 0.95 \\
\hline & $1960-70$ & 3.24 & -1.02 & -2.79 \\
\hline & $1970-80$ & -0.47 & -1.68 & -2.52 \\
\hline & $1980-90$ & 3.33 & 0.40 & -0.92 \\
\hline
\end{tabular}

Notes:

1. All rates in percents.

2. The rate $\mathrm{r}\left(\mathrm{N}_{5-6}\right)$ represents average annual change over the decade in the size of the 5-6-year-old resident population.

3. Other rates refer to the average annual change in cohort measures between the birth cohort, which was 5-6 at the start of the decade, and the birth cohort, which was 5-6 at the end of the decade. For example, the r(B) rate for 1950-1960 measures the average annual growth in state births between 1943-44 and 1953-54. 
( -0.17 percent per year); (3) changes in survival rates between the 1943-44 and 1953-54 state birth cohorts (approximately +0.24 percent per year, based on infant survival statistics); and (4) changes in net migration of preschool age children between the 1943-44 and 1953-54 cohorts (-1.61 percent per year). Alternatively, effects (1) and (2) can be added to get the effect of the change in the number of West Virginia births: $r(B)=1.11$ percent -0.17 percent $=0.95$ percent.

\section{DISCUSSION OF RESULTS}

\section{Cross-State Comparisons}

Figure 2 displays, from top left, the contributions of changing crude birth rates $r(b)$, total state births $r(B)$, infant survival rates $r(s 1)$, and net migration rates $r(m 5-6)$ to the overall growth rates in Figure 1.

Several important points are immediately apparent in Figure 2. First, as intuition suggested, historical fluctuations in fertility (top left panel) have had a strong impact on trends in numbers of SE children in all three states. In addition, these states share a common temporal pattem in the effects of changing birth rates on state 5-6-year-old populations. In short, the baby boom and subsequent bust had similar effects on all three states, and these effects were the primary determinants of change in SE populations.

Second, mortality effects are very small relative to the impact of other demographic changes (bottom left; note the difference in scales in the panels). Continuing improvement in the survival chances of newborns has been a positive force for the growth of SE populations in all three states, but improved survival has not contributed significantly to SE population growth. The small positive effects of mortality decrease have been similar across states during the 1950-1990 period.

Third, despite the relatively short time between birth and school entry, migration trends among very young children (bottom right) have had important effects on states' SE population growth. These effects differ considerably across the three states studied, as one might expect from their very distinct migratory histories.

The signs of some migration effects are surprising, in the manner of the example above. In the absence of other demographic changes, for example, migration trends would have reduced Florida's 5-6-year-old population by nearly 2 percent per year during the 1960 s. This occurred not because there were net outflows of very young children from Florida, but rather because net inflows were decreasing. A similar effect appears for West Virginia during 1960-1970, where a 
FIGURE 2

Contributions of Changes in Demographic Components to the Growth of 5-6Year-Old Resident Populations-Florida (F), South Carolina (S), and West Virginia (W)

Lagged Crude Birth Rate

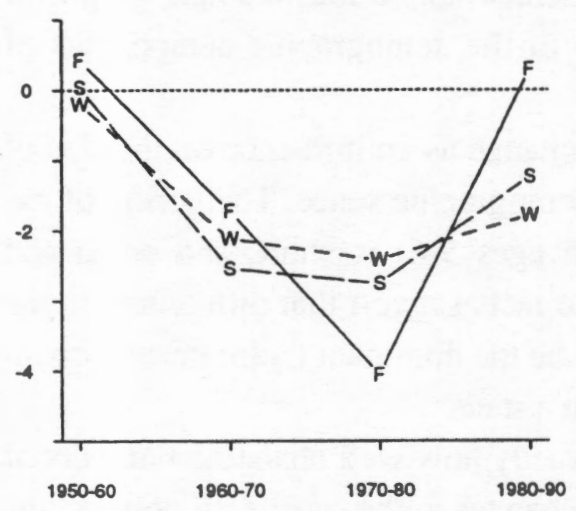

Infant Survival

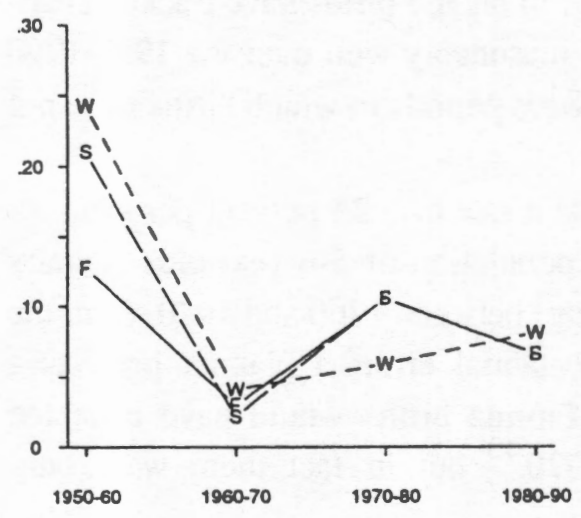

Lagged Births

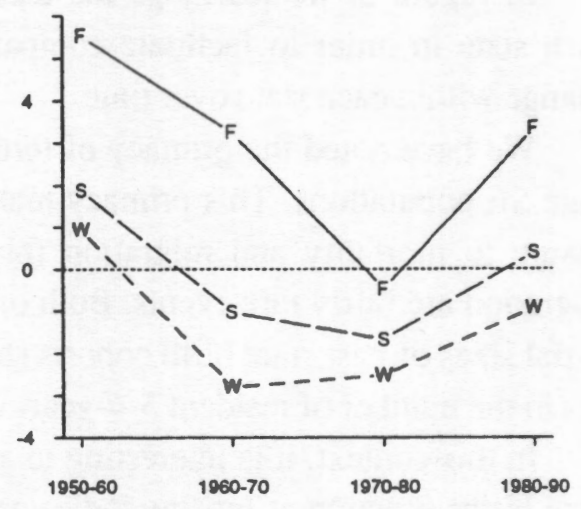

Migration

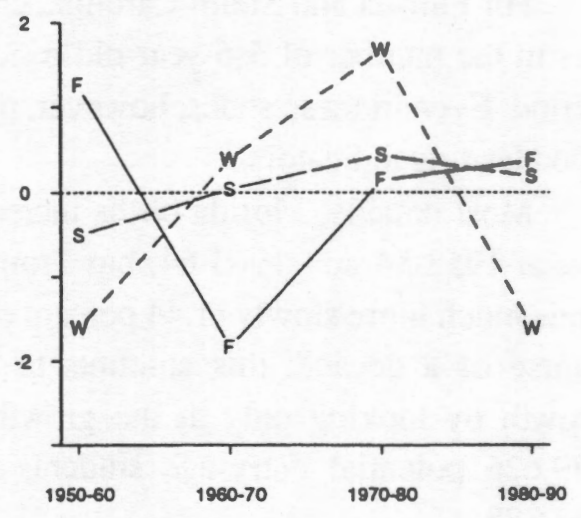

Note differences in vertical scales between panels. All rates in percents. 
decrease in net outflows over the decade had a positive effect on the growth of the SE population. In contrast, the positive migration effect for West Virginia during the next decade, 1970-1980, actually represented a shift from net outflows for the 1963-64 state birth cohort $(m=0.9128)$ to net inflows in the 1973-74 cohort $(\mathrm{m}=1.0787)$.

\section{A More Detailed Look at State Histories}

In Figure 3, we rearrange the data presented above into a single graph for each state in order to facilitate comparison of the demographic components of change within each state over time.

We have noted the primacy of fertility change as an influence on the size of state SE populations. This primacy makes demographic sense. The period of exposure to mortality and migration (birth to ages 5-6) is short, and death and migration are fairly rare events. Both of these facts suggest that differences in the initial sizes of past state birth cohorts should be the dominant factor driving changes in the number of resident 5-6-year-olds in a state.

In this context, it is interesting to ask exactly how well changing numbers of state births function as leading indicators of changes in the size of SE populations 5-6 years later. If lagged births were perfect leading indicators, then the $r(N)$ and r(B) series would overlap completely for each state in Figure 3.

For Florida and South Carolina, changes in lagged births have tracked changes in the number of 5-6-year-old residents reasonably well over the 1950-1990 period. Even in these states, however, there were periods in which births were not good leading indicators.

Most notably, Florida births increased at a rate of 3.24 percent per year between 1953-54 and 1963-64, but Florida's population of 5-6-year-olds actually grew much more slowly (1.44 percent per year) between 1960 and 1970. Over the course of a decade, this amounts to a substantial error: a planner projecting growth by looking only at the growth of Florida births would have expected 279,626 potential entry-age students in $1970,{ }^{13}$ but in fact there were only 233,388.

Who were the 46,000 missing kindergartners? Loosely speaking, they were young residents of New York, Ohio, and other states who would have moved to Florida by age 5-6 if their migration pattems had been similar to those of their predecessors bom 10 years earlier. Because inflows had slowed since the 1950s, however, these children had not moved to Florida before reaching school age. This corresponds to the negative migration effect cited above for Florida in the 1960s: the cohort that was 5-6-years-old in 1970 had not grown as much through 


\section{FIGURE 3}

Average Annual Intercensal Growth Rate of 5-6-Year-Old Resident Population (N), Decomposed into Contributions of Changes in State Births (B), Infant Survival (s), and Migration (m)

Florida

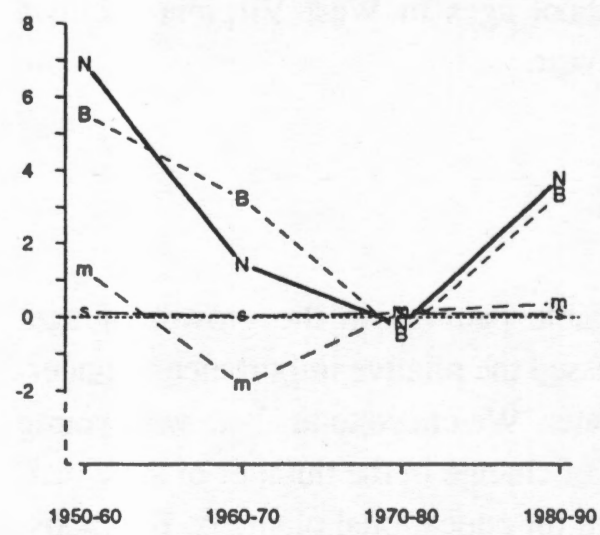

South Carolina

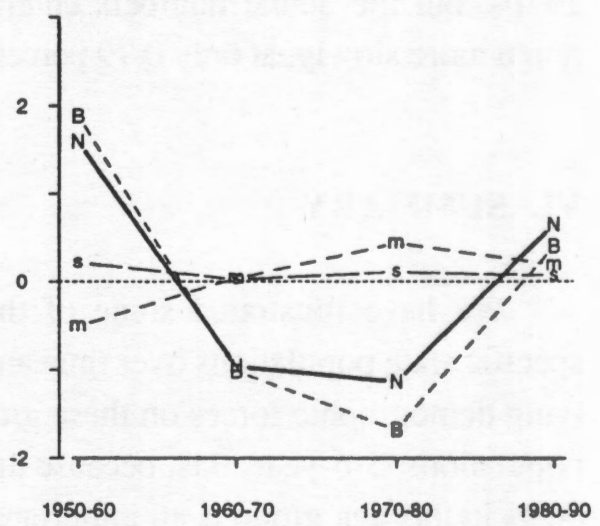

West Virginia

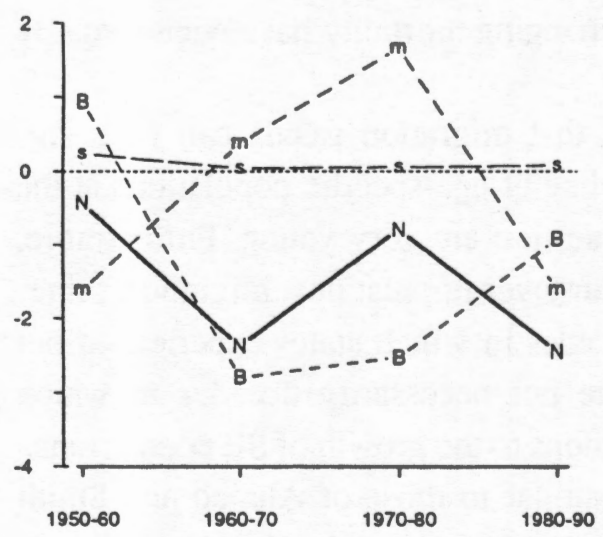

Note: All rates in percents. 
migration as had earlier cohorts, and a projection that did not incorporate this effect would have overestimated the 1970 SE population.

In contrast to the general pattem in Florida and South Carolina, consistently large migration effects in West Virginia have made births poor predictors of upcoming changes in SE populations. In three of four decades studied, $r(B)$ and $r(N)$ differed greatly. For example, analysis of state births would have predicted an increase of 0.95 percent per year in the number of West Virginia 5-6-year-olds during the 1950s, but in fact the number of 5-6-year-olds decreased at 0.42 percent per year. Similarly, lagged births declined at 2.52 percent per year over the 1970s, but the actual numbers entering school ages in West Virginia declined much more slowly, at only 0.79 percent per year.

\section{SUMMARY}

We have illustrated some of the possible patterns in the growth of agespecific state populations over time and assessed the relative importance of underlying demographic forces on these growth rates. We chose to analyze very young populations, 5-6-year-olds, because the rate of change in the number of state residents in this age group is an important datum for educational planners. By choosing such a young age group, we implicitly stacked the deck against finding large effects for mortality and migration in our decompositions.

We did, in fact, find that fertility changes have the largest influence on future SE populations. In addition, the effects of changing mortality have been virtually nil in the states studied here.

Our examples demonstrate, however, that migration trends can be a significant factor affecting the growth and decline of age-specific populations at the state level, even when the age groups in question are very young. Furthermore, because age groups are by definition high-turnover populations, migration sometimes works in rather surprising ways. Decades in which states experienced net inflows (outflows) of young children were not necessarily decades in which migration made positive (negative) contributions to the growth of SE populations.

Broadly interpreted, our findings are similar to those of Ahmed and Smith (1992), despite the fact that they examined state-level growth of a very different age group (65+). Like them, we find that age-specific growth within a state is driven in large part by past fertility fluctuations. In their analysis, these effects are incorporated in "momentum"; in our case, only very recent fertility history is relevant, blurring the distinction between "current" and "past." The logic, however, is similar. Also like Ahmed and Smith, we find that although current migra- 
tion trends are a secondary influence on the numbers of state residents at specific ages, such trends are often important in explaining interstate differences.

In sum, changes in the number of in-state births are generally good, but not perfect, predictors of future changes in states' SE populations. Accurate fertility projections are necessary, but not sufficient, for accurate projections of states' SE populations. The choice of geographic unit also affects the relative importance of migration. Had we chosen even smaller units-e.g., counties-local births would be poorer leading indicators, and the effects of changing migration would be relatively more important.

As a final point, we note that census-based population projections typically take several sets of recently observed interstate migration rates and develop alternative projections by using alternative sets of constant rates. As we have noted, trends in migration can significantly affect age-specific population growth, even at young ages and over short time periods. Because constant migration rates imply $r(m)=0$, standard projection methods typically assume away one of the components of age-specific population growth. Planners and researchers using censusbased projections need to be aware of this fact, particularly in an era in which fertility trends are widely expected to become a less important source of population change at both the state and national level. Given the volatile nature of migration effects in our small sample of states, it is advisable to consider a wider range of migration scenarios, including some in which migration rates change during the projection period.

\section{ENDNOTES}

1. For example, if Alabama had relatively few 15-29-year-olds and many 55-64-year-olds in 1970, then one would expect an increasing proportion of Alabama's population to be $65+$ years-old by 1980 , even if migration were zero and vital rates remained constant. This would occur because past demographic pattems have built a 1970 Alabama population that will experience few births and many 65 th birthdays in the 1970 s.

2. Of course, past mortality and migration also affect the start-of-decade age distributions. Migration will play a larger role in determining the initial age distribution of states than it does for national populations and may be especially influential in states such as Florida. Even at the state level, however, the fertility history of the population remains the primary influence on age structure. Thus, one may cautiously interpret the strong momentum effect found in Ahmed and Smith (1992) as indicating a strong effect of past fertility trends.

3. Interested readers can reproduce the analysis for any of the 50 states with the decomposition method presented in this section. 
4. If time and age are measured on a continuous scale, then strictly speaking Equation (1) gives the density of population at exact age $x$, rather than the number of $x$-year-olds. This distinction is not important for our purposes, however.

5. Changes in $b$ result from changes in the age composition of the state population as well as from changes in age-specific fertility rates. Nevertheless, $\mathrm{r}(\mathrm{b})$ is a good, "crude" indicator of state fertility trends.

6. For example, Florida's govemor has stated (1991) that approximately 1,000 people move to Florida each day, and that each day's entries create a need for two additional school classrooms. This may be incorrect. One cannot assess the need for new classrooms without knowing how many of the occupants of today's classrooms were themselves migrants to Florida. It is logically possible that 1,000 migrants per day could imply a decrease in the need for Florida classrooms, if movement into Florida occurred at much higher rates in the past.

7. We performed a similar analysis for the age groups at which students typically begin secondary school (13-14-year-olds). Results for this other age group are not reported here, but are available from the authors on request.

8. U.S. decennial census counts report the population on April 1. It is more convenient to work with January 1 counts because the other data are reported by calendar year. This translation does not affect the paper's results in any important way. To obtain estimated counts of 5-6-year-olds on January 1, 1950, we extrapolated the April 1, 1950, census counts backward by three months using the April 1, 1950, to April 1, 1960, growth rate for each state.

9. Note that our use of two-year birth cohorts means that $P$, a measure of exposure, should be approximately equal to twice the average state population over the two-year interval.

10. Although we have no direct evidence on cohort mortality by state, published period data allow us to evaluate the magnitude of the error introduced by our use of $s_{1}$ as an estimate of cohort mortality through age five. For example, a U.S. period life table for 1939-41 (Greville 1947) estimates a survival probability of 0.989 between exact ages one and five. Period life tables for Florida, South Carolina, and West Virginia 40 years later (1979-81) all estimate this probability at 0.997 (U.S. Department of Health and Human Services 1986). This suggests (1) that the systematic errors introduced into residual-based migration estimates are small, especially in recent periods, and (2) that cohort survival rates between ages one and five have changed on the order of hundredths of percentage points per year over the period under study, thus representing a negligible influence on our analysis.

11. Using residual migration measures is unappealing, but it cannot be avoided when using historical census data. For some of the states and time periods under study, we were able to compare our $\mathrm{m}_{\mathrm{x}}$ estimates with net migration es- 
timates from other sources. These other sources also used residual measures, but they did not suffer from the systematic bias built in by our use of infant mortality only. Our net migration estimates were virtually identical to previous estimates, from which we conclude that the bias in our estimates is negligible. This conclusion applies a fortiori to analysis of cross-cohort differences in $\mathbf{m}_{\mathbf{x}}$.

12. The data in Tables 1 and 2 were gathered from many separate sources, all of which are included in the list of references.

13. Based on 202,140 5-6-year-olds in 1960, combined with the fact that the 1963-64 Florida birth cohort was 1.383 times larger than the 1953-54 cohort.

\section{REFERENCES}

Ahmed, Bashir, and Stanley K. Smith. "How Changes in Components of Growth Affect the Population Aging of States." Journal of Gerontology 47, no. 1 (1992): S27-37.

Greville, Thomas N. E. United States Life Tables and Actuarial Tables 1939-41

(Table 1). National Office of Vital Statistics. Washington, D.C.: U.S. Government Printing Office, 1947.

Horiuchi, S., and S. H. Preston. "Age-Specific Growth Rates: The Legacy of Past Population Dynamics." Demography 25, no. 3 (1988): 429-441

Nam, Charles B., and T. J. Mathews. "Population Dynamics and Student Enrollment Potential in the Southem States 1950-2010." Florida State University, Center for the Study of Population Working Paper 92-89, 1991.

Preston, S. H., and A. J. Coale. "Age Structure, Growth, Attrition, and Accession: A New Synthesis." Population Index 48 (1982): 217-259.

Preston, S. H., C. Himes, and M. Eggers. "Demographic Conditions Responsible for Population Aging." Demography 26, no. 4 (1989): 691-704

Shryock, Henry S., Jacob S. Siegel, and Associates. The Methods and Materials of Demography. New York: Academic Press, 1976.

Smith, Stanley K., and Bashir Ahmed. "A Demographic Analysis of the Population Growth of States, 1950-1980." Journal of Regional Science 30, no. 2 (1990): 209-227.

State of Florida. Florida Vital Statistics 1968, 1978, 1988. (1968: Tables B,11; 1978: Tables B,K; 1988: Tables E,L). Jacksonville, 1969, 1980, and 1990.

State of South Carolina. South Carolina Vital and Morbidity Statistics 1975, 1988. (1975: Tables 1,2; 1988: Tables 2,7) Columbia, 1977, 1990.

U.S. Department of Commerce. Vital Statistics Rates in the United States 19001940. Tables I, 26, 44. Washington, D.C.: U.S. Government Printing Office, 1943. 
. Census of Population: 1950, 1960, 1970, 1980. (1950: Volume 2, Table 51; 1960: Volume 1, Table 94; 1970: Volume 1, Table 19; 1980: Volume 1, Table 18). Washington, D.C.: U.S. Government Printing Office, 1952, 1963, 1973, and 1983.

U.S. Department of Health, Education and Welfare. Vital Statistics Rates in the United States 1940-1960. Tables 19, 41, 80. Washington, D.C.: U.S. Government Printing Office, 1968.

. Vital Statistics Rates of the United States 1962, 1967, 1972, 1977. (All years: Volume 2 - Mortality Table 2-6). Washington, D.C.: U.S. Government Printing Office, 1964, 1969, 1976, and 1981

Vital Statistics of the United States 1970, 1980, 1987. (1970: Volume 1, Natality Table I-45; 1980 and 1987: Volume 1, Natality Table I47). Washington, D.C.: U.S. Government Printing Office, 1970, 1984, and 1989.

U.S. Department of Health and Human Services. U.S. Decenial Life Tables for 1979-81, Volume 11 (\#10-FL,\#41-SC,\#49-WV). Washington, D.C.: U.S. Government Printing Office, 1986.

West Virginia Division of Health. Vital Health Statistics of West Virginia 1988. Exhibit 17, Table 4. Charleston, 1989.

Wetrogan, Signe I. Projections of the Population of States by Age, Sex, and Race: 1989 to 2010. U.S. Bureau of the Census, Current Population Reports, Series P-25 No. 1053. Washington, D.C.: U.S. Government Printing Office, 1990. 